\title{
Numerical investigation of friction crush welding aluminium and copper sheet metals with flanged edges
}

\author{
Ashu Kumar $^{1 *}$, Gurinder Singh Brar² \\ ${ }^{1}$ Research Scholar, Department of Mechanical Engineering, National Institute of Technology Uttarakhand, Srinagar (Garhwal), \\ Uttarakhand, India \\ ${ }^{2}$ Department of Mechanical Engineering, National Institute of Technology Uttarakhand, Srinagar (Garhwal), Uttarakhand, India
}

\begin{abstract}
Aluminum alloys are the most attractive solutions for many industries including aerospace, marine, and other transportation sectors where lightweight construction is required. Friction Crush Welding (FCW) is a new material joining process that simultaneously creates a mechanical lock and a metallurgical seal at the interface between similar and dissimilar materials. In this research work presents the development of numerical modelling to predict the temperature distribution and mechanical performance of aluminum and copper similar joints in the FCW of sheet metal section. An explicit nonlinear transient finite element thermomechanical model is develop using ABAQUS based on the coupled Euler-Lagrange method to simulate FCW of AW5754 and Cu-DHP alloys. The Johnson-Cook materials law is adopted in the FEM. Numerical investigations of the FCW process was performed to reduce experimental testing times, which can be long and expensive. Temperature distribution and von misses stress flow patterns are observed at the top surface of the weld. Numerical simulation data correlate with experimental data in the literature.
\end{abstract}

\section{Introduction}

Aluminum alloys have been prime candidates for material selection in industries such as commercial and military aircraft and shipbuilding for over 80 years, because of their mechanical properties, design, and of their well-known performances, and the availability of good control methods. The predominant use of aluminum in various fields is the search for a practical and efficient aluminum bonding technique that does not endanger the required mechanical, chemical, and metallurgical properties of the material [1]. Aluminum is unique weld metal because aluminum does not solidify when it cools. The high temperatures that occur during fusion welding have a significant influence on the metal structure and have a direct effect on its properties and behavior [2]. Aluminum alloys have excellent corrosion resistance, especially in seawater and polluted atmospheres. Therefore, it is very suitable for use in the marine industry. Most often, aluminum alloys are used in shipbuilding, chemical welding, and nuclear armor [3]. Copper and its alloys have various technical applications such as heat exchangers, hot water tanks, or pressure tanks for nuclear reactors. Most of these designs are welded [4].

M.R. Milan et al. [3] studied torsion and impact tests in three aluminum alloys: AA 5754-H111, AA 6082-T6, and AA 2024-T351. Tests are performed which include various pressure stress triaxialities and load parameters. These experiments are modeled with FE models basis of critical plastic deformation, Johnson-Cook, and BaiWierzbicki. M. A. Constantin et al. [4] studied a threedimensional coupled Euler-Lagrange (CEL) FE model of the FSW process for pure copper plates. The mass scaling process with which the computation time is shortened and its effect on the distribution of temperature range.

ABAQUS/Explicit Coupled Eulerian-Lagrangian method was used to create a 3D finite element-based model of FSW with the strain-rate and Johnson-Cook law [4, $12,13,14,17,18]$. C. Wu et al. [15] developed a 3D model for simulates the temperature and flow of plastic in the FSW of an aluminum alloy. They observe that there is a strong flow of plastic near the shear layer of the tool and the speed of the tool has an important effect on flowing velocity. The method for calculating the total content stream is optimized with visual results using indexing techniques. In order to overcome the drawbacks of pure Lagrange and Euler descriptions, arbitrary Lagrange-Euler (ALE) formulations, adaptive meshing and mass scales have used as methods to improve the sequential simulation of the friction welding process[16, 20]. M. Iordache et al. [16] observed maximum temperature value obtained is lower compared to other similar studies and this is explained by using a lower speed rotation of the work tool. Z. Zhu et al. [17] studied a three-dimensional thermomechanical model Al6061-T6, associated with finite

* Corresponding author: ashu1651@gmail.com 
elements, analyze the defects formation in FSW and the model allows to accurately predict the shape of plastic deformation and the presence of a gap in the weld. J. Xiong et al. [18] developed a 3D FE model for friction spot welding of 2524-T3 aluminum alloys based on ABAQUS / Explicit. They observe that the heat release due to friction and plastic deformation improved and the stress decreased as the speed increased. M. Nourani et al. [19] developed a multiphysics integrated model FSW of aluminum 6061 that combines various dynamically incompressible fluids, non-thermal states, and conductivity. They predict the temperature distribution, strain, and strain rate around pins during welding. N. K. Salloomi et al. [20] studied the simulation of the FSW process for 6061-T6 aluminum alloy T-joint using the FE method. B. Ahmad et al. [21] was developed a DH36 low alloy steel friction stir welding $3 \mathrm{D}$ model in the Abaqus / Explicit software. They suggest that fast welding parameters can be used when higher productivity of weld quality is desired, and slow welding parameters can be used when superior weld quality is preferred.

Friction crush welding (FCW) is a technique recently developed by F. A. Besler et al. (2016) can be used for welding the same and different materials with and without filler material. This process involves welding between two parts due to the relative movement between the parts and a rotating cylindrical tool with a certain profile shape, as shown in Fig.1. Flange parts are located nearby and feed the tool at a constant speed, since the material is crushed, and the crushed material fills the space between the plates with the tool and creates weld $[5,6]$.

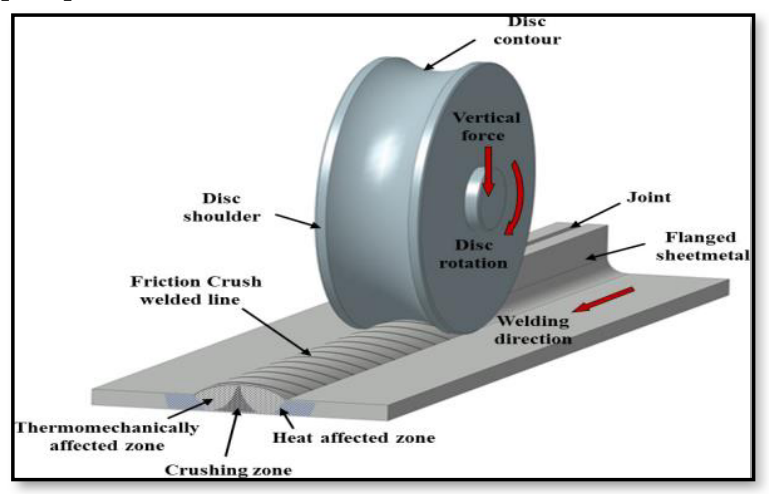

Fig. 1. Design of Friction Crush Welding [5]

F. A. Besler et al. [5, 6] investigated a new welding technique called friction crush welding for the production and analysis of flange edges of sheet metal in three metals: aluminum (EN AW 5754H22), copper (DHP), and steel (DC01)used tool speed of (1200018,000) rpm. F. A. Besler et al. [5] observed welding yield strength was $95 \%, 90 \%$ and $64 \%$ of the parent metal for steel, aluminum, and copper, which is a function of the number of revolutions of the rotating wheel and feed rate $(250-7000 \mathrm{~mm} / \mathrm{min})$. F. A. Besler et al. [6] studied the welding of $1 \mathrm{~mm}$ thick sheets with additional wire of welding and feed rate (2000-10,000 $\mathrm{mm} / \mathrm{min}$ ). The observed average yield strength was $98 \%, 77 \%$ and $69 \%$ of the parent metal for steel, aluminum, and copper. Brar and Jamwal [7] investigate the Friction crush welding of aluminum alloy 6061 T-6 with a thickness of $2 \mathrm{~mm}$ with a spherical tool profile at 220 - $740 \mathrm{rpm}$ and the corresponding feed supply 15- 45 $\mathrm{mm} / \mathrm{min}$. The result shows that the bond strength of the welded joint increases with increasing tool speed and feed rate. G. S. Brar et al. [8] optimized the parameters of the welding process in stainless steel (AISI 304), produced by friction crush welding using Taguchi optimization technology. The optimal parameters observed were $750 \mathrm{rpm}$ and 45 feed rate, resulting in a maximum bonding force of 13693 N. P. Singh et al. [9, 11] investigated that dissimilar weld of aluminum and stainless steel using the FCW technology. They observe that FCW welding has good diffusion, mutual vision, and high tensile strength between dissimilar metals compared to MIG welding technology. A. S. Joma et al. [10] studied the FCW of flanged edges of oxygen-free copper sheets at different tool speeds (220-1500 rpm) and feed rates $(20-150 \mathrm{~mm} / \mathrm{min})$ were used to weld. They observed maximum strength of $105 \mathrm{MPa}$ and hardness of $63 \mathrm{HV}$ at a tool speed of $1500 \mathrm{rpm}$ and a feed rate of $115 \mathrm{~mm} / \mathrm{min}$. The reduced hardness in the crushing zone compared to other zones was associated with the heat of friction and the flow of plastic. P. Singh et al. [11] investigate the effect of FCW inputs such as tool rotation and feed rate on weld output using the Taguchi L9 technique. The optimal process parameters for Taguchi weld strength were a tool speed of $740 \mathrm{rpm}$ and a feed rate of $45 \mathrm{~mm} / \mathrm{min}$. The theoretical bond strength was $0.676 \%$ higher than the calculated value of the experimental bond strength.

In the present work numerical investigations is developed to simulate the temperature distribution of sheet metal of aluminium AW-5754 and copper Cu-DHP alloy for similar material using friction crush welding technique and validate with the literature

\section{Description of the FEM Model}

A 3D FE model is developed using ABAQUS for prediction and analyse of the formation of the distribution of temperature during the FCW process based on the coupled Euler-Lagrange formulation, Coulomb's law of friction, and the Johnson-Cook plasticity law. In this model work pieces are deformable and the tool is rigid, the workpiece is supposed to be made of elastic-plastic material.

\subsection{Geometric model}

There are various process parameters that can affect the friction crush welding process. Two important parameters, namely the tool geometry and the joints design.

The design of the friction tool can have a significant impact on the flow of material and the formation of the welding line. The main dimensions of the disc can be found by three parameters: the external diameter of the disc (D), the width of the disc $\left(\mathrm{W}_{\mathrm{d}}\right)$, and the curvature of the disc surface $\left(d_{c}\right)$ shown in Fig. 2. Based on the gap and size of the two sheet metal flange pieces, a geometric consideration was devised to determine the geometric dimensions of the friction disc. As an initial concept, the tool (disc) has a simple semi-circular 
groove on the outer circular surface that rotates around its central part. The purpose of this concave profile was to create a restriction on the material concentrated in the centre of the weld. Due to this better horizontal mixing of the material in the crushing area, which leads to better bonding strength. Another desired effect was the createon of a convex weld line with a reinforcing effect on the

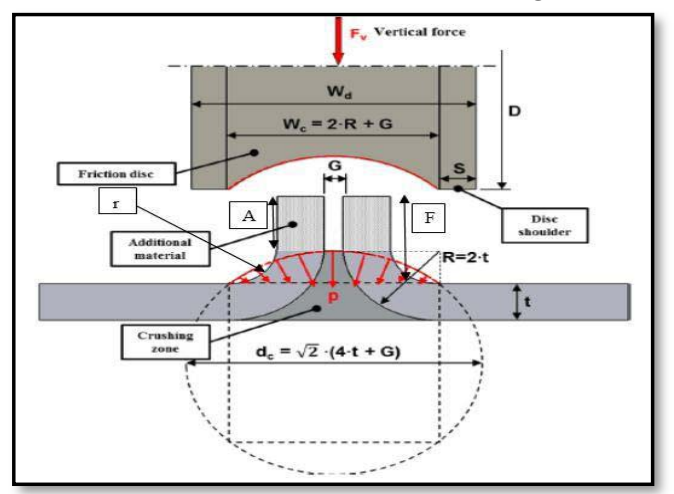

Fig. 2. Welding tool (disc) geometry in the crushing zone.[5] connection geometry $[5,6]$. The size of the workpiece is $250 \mathrm{~mm} \times 75 \mathrm{~mm} \times 1 \mathrm{~mm}$ and Fig. 3 shows the material assignment (by colour).

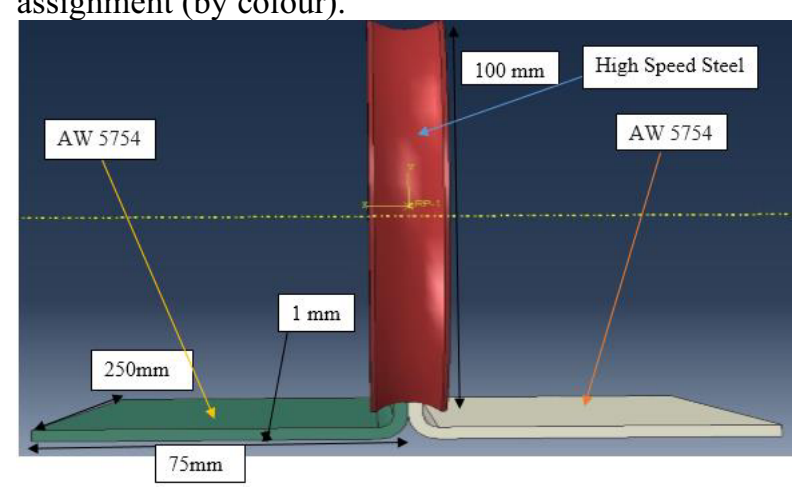

Fig. 3. The geometry of the model

According to the CEL method, the workpiece was based on the Eulerian method, while the FCW tool is configured as a Lagrangian body. The Euler region is associated with 60,444 Euler components with 5 thermally coupled nodes. To increase the efficiency of the calculations, the inclined mesh technique was used to create a fine mesh in the area of interaction of the toolworkpiece zone and a coarse mesh on the sides. In contrast, the FCW tool was considered a rigid isothermal Lagrangian body.

\subsection{Material model}

The Johnson-Cook material model was used to describe the flow stress as a function of strain hardening, strain rate hardening, and temperature softening as follows [13].

$$
\begin{aligned}
& \sigma=\left(A+B \varepsilon^{n}\right)\left[1+C \ln \left(1+\frac{\dot{\varepsilon}}{\dot{\varepsilon} o}\right)\right][1- \\
& \left.\left(\frac{T-\text { Troom }}{\text { Tmelt-Troom }}\right)^{m}\right]
\end{aligned}
$$

Where $\varepsilon$ is the equivalent plastic strain, $\varepsilon$ is the equivalent plastic strain rate, $\dot{\varepsilon} O$ is the reference strain rate, Troom is the reference temperature and Tmelt is the melting point. $\mathrm{A}, \mathrm{B}, \mathrm{n}, \mathrm{C}$, and $\mathrm{m}$ are the constants dependent on the material.

In the present model, the thermal and mechanical properties as well as Johnson-Cook parameters of AW5754 and $\mathrm{Cu}-\mathrm{DHP}$ (Tables 1 and 2, respectively) can be found in the literature [3],[4].

Table 1. Johnson-Cook plasticity model constants for AW5754 and $\mathrm{Cu}-\mathrm{DHP}$ [3],[4].

\begin{tabular}{|c|c|c|}
\hline \multirow{2}{*}{$\begin{array}{c}\text { Johnson-Cook } \\
\text { Parameter }\end{array}$} & \multicolumn{2}{|c|}{ Alloys } \\
\cline { 2 - 3 } & AA-5754 & Cu-DHP \\
\hline A (Mpa) & 28.13 & 90 \\
\hline B (Mpa) & 278.67 & 292 \\
\hline $\mathrm{n}$ & 0.183 & 0.31 \\
\hline $\mathrm{C}$ & 0.00439 & 0.025 \\
\hline $\mathrm{m}$ & 2.527 & 1.09 \\
\hline$\varepsilon$ & 0.1 & 0.1 \\
\hline $\mathrm{T}_{\text {room }}(\mathrm{K})$ & 293 & 293 \\
\hline $\mathrm{T}_{\text {melt }}(\mathrm{K})$ & 873 & 1083 \\
\hline
\end{tabular}

Table 2. Material properties for AW-5754 and Cu-DHP used in model [3], [4].

\begin{tabular}{|c|c|c|}
\hline \multirow{2}{*}{ Material properties } & \multicolumn{2}{|c|}{ Alloys } \\
\cline { 2 - 3 } & AA-5754 & Cu-DHP \\
\hline Density $\left(\mathrm{kg} / \mathrm{m}^{3}\right)$ & 2700 & 8913 \\
\hline Elastic modulus $(\mathrm{GPa})$ & 68 & 117.2 \\
\hline Poisson's ratio & 0.3 & 0.33 \\
\hline Specific heat, $\mathrm{Cp}(\mathrm{J} / \mathrm{Kg}-\mathrm{K})$ & 900 & 385 \\
\hline Thermal conductivity $(\mathrm{W} / \mathrm{m}-\mathrm{K})$ & 147 & 388 \\
\hline Thermal expansion $\left(10^{-6} / \mathrm{K}\right)$ & 24 & 16.8 \\
\hline
\end{tabular}

\subsection{Boundary conditions}

In the current FCW model, the main source of heat is friction between the rotary tool and the plate. The friction coefficient of the moving phases must be 0.4 ,

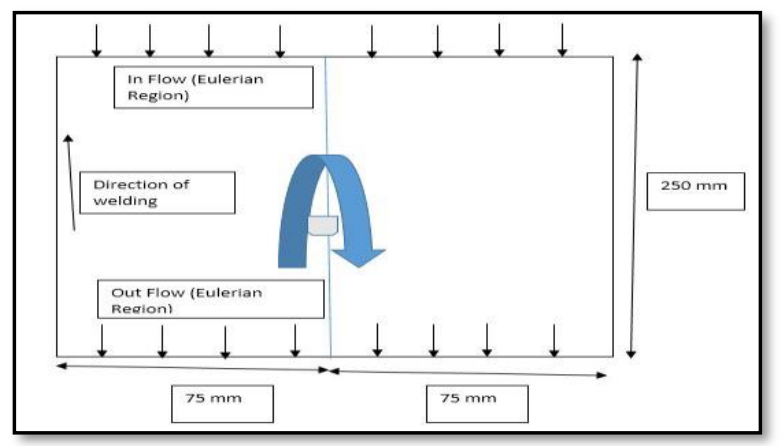

Fig. 4. Boundary condition

applied using the type of surface-to-surface contact (explicit) available on ABAQUS. Here we assume that $100 \%$ of the friction work and $90 \%$ of the plastic work were distributed in the heat release due to the complex heat conduction between tool and specimen, the total friction heat was distributed through each part using the following equation [13].

$$
\mathrm{f}=\left(\frac{\lambda 1 \mathrm{p} 2 \mathrm{Cp} 2}{\lambda 2 \mathrm{p} 1 \mathrm{Cp} 1}\right)^{1 / 2}
$$

where $p$ is the density, $\mathrm{Cp}$ is the specific heat and $\lambda$ is the thermal conductivity. The subscripts 1 and 2 respectively delegate tool and workpiece. In the simulation, both the tool speed (18000 revs/min ) and 
the welding speed $(500 \mathrm{~mm} / \mathrm{min})$ are enforced on the tool reference point, while the plate is fixed at the bottom and sides. The model uses the boundary condition of convection heat transfer. Assume convection coefficient [13] of $30 \mathrm{~W} / \mathrm{m}^{2}-\mathrm{K}$ at the top and sides of the plate is used to simulate heat dissipation in the atmosphere. In this model, the inlet flow and outlet flow surfaces of a part are considered Euler region types, where the mesh does not follow the material movement. The top, bottom, and side surfaces of the workpiece are considered a type of slip area where the mesh is forced to move with the material in a direction perpendicular to the boundary.

As already mentioned, due to low computational efficiency, only the local area of the part was included in the analysis and the welding step was simulated using a control volume approach. For simplicity, the FCW tool was set as a reference point to precisely control its movement. The longitudinal movement of the FCW tool was not explicitly taken into account. Instead, the longitudinal speed of the tool is zero and the specimen material could pass through the Euler region at an overall negative longitudinal speed with respect to the welding speed. This was achieved by using appropriate boundary conditions for the inlet and outlet speeds on the vertical faces of the Euler domain, which are orthogonal to the tool movement. In addition, the top of the workpiece is free and boundary displacement stresses are applied to prevent material from escaping from the sides and bottom of the Euler region. The welding process conditions used in the model, including tool speed and welding speed, are exactly the same as those in the welding experiment.

\section{Validation}

This model is carried out by comparing the temperatures calculated in a steady state with those of Besler et al. [6] for the same processing conditions of FCW. The evolution of the temperature calculated on the welded face, from the centre of the tool, compared to that measured in [6] for a similar friction crush welding. Fig.

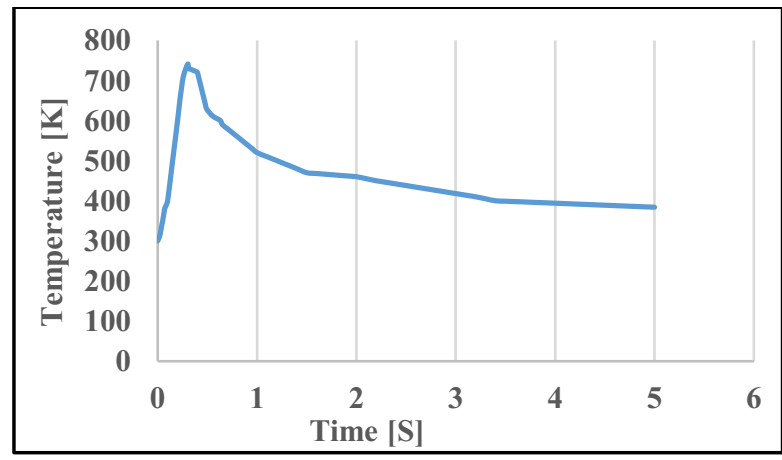

Fig. 5. Temperature distribution in Copper Sheetmetal plates (Finite Element Analysis v/s F. A. Besler, et al.)

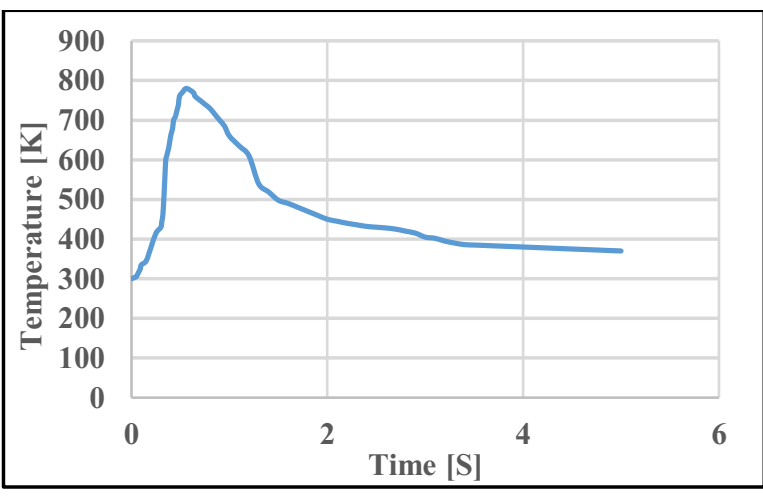

Fig. 6. Temperature distribution in Aluminium Sheetmetal

plates (Finite Element Analysis v/s F. A. Besler, et al.)

5 and 6 show for the Cu-DHP and AW-5754 respectively the difference between the maximum temperatures measured at [6]. The estimated temperatures calculated for the AW-5754 and $\mathrm{Cu}-\mathrm{DHP}$ the axis of the welded line on both sides and compare temperature value are found between 12-20\% Part of comparison between the calculated and measured values can be allocated to the precision of the temperature measurement, as reported by the authors in [6].

\section{Result and discussion}

\subsection{Temperature distribution}

Parameters of interest include temperature distribution, strain rate, plastic deformation, material distribution, von Misses stresses in the weld component, and material velocity profiles developed around an FCW tool.

Fig. 7 clearly seen that the distribution of temperature around the centre line of the weld joint is asymmetric, which occurs due to different flow of material around the tool. Fig. 6 shows the peak temperature is $740{ }^{\circ} \mathrm{C}$ is approximately $85 \%$ of the melting point $\left(873{ }^{\circ} \mathrm{C}\right)$ of AW-5754 aluminum alloys, which is lower than the material melting point and Fig. 5 shows the peak temperature is $780{ }^{\circ} \mathrm{C}$ is approximately $72 \%$ of the melting point $\left(1083{ }^{\circ} \mathrm{C}\right)$ of $\mathrm{Cu}-\mathrm{DHP}$ Copper alloys, which is lower than the material melting point.

The distribution of von misses stress profiles shown in Fig. 10 and show that the contact surface between disc and material has an almost zero elastic limit. This is the result of using the Johnson-Cook material model. When the material reaches the solidus temperature, the yield

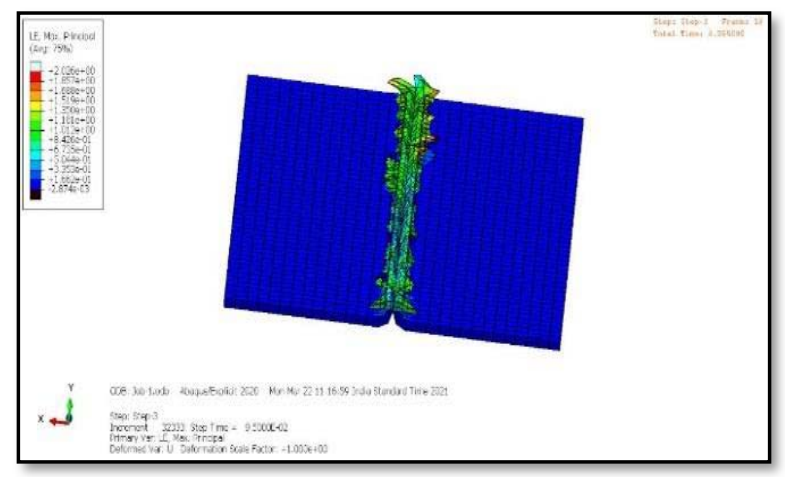

Fig. 7. Temperature distribution of AW-5754 
point approaches zero. The distribution of the material over the treated area was mixed for the thickness of the plate.

Fig. 5 and 6 compare the expected results with the data measured for the maximum temperature distribution along the vertical direction of the weld. Clearly seen that the maximum simulation temperatures are almost the same as the experimental temperatures (literature). The difference can be allocated to the material variables use in the numerical simulation, to the assumption of a constant friction coefficient, and to the simplification of the thermal boundary conditions. In addition, the measurement error of the temperature range influences simulation results. There is a difference between the simulation temperature and the measured data, they generally do not coincide with each other but are still in good agreement. Fig. 7 and 8 show the change in temperature during the crushing phase ( 1 to 5 seconds). First, the rotary tool began to press the plate, crushing the material, and a semi-circular temperature profile is found. The temperature distribution around the tool was found to be nearly constant, as shown in Fig.8 Furthermore, distribution is observed on the plate, as

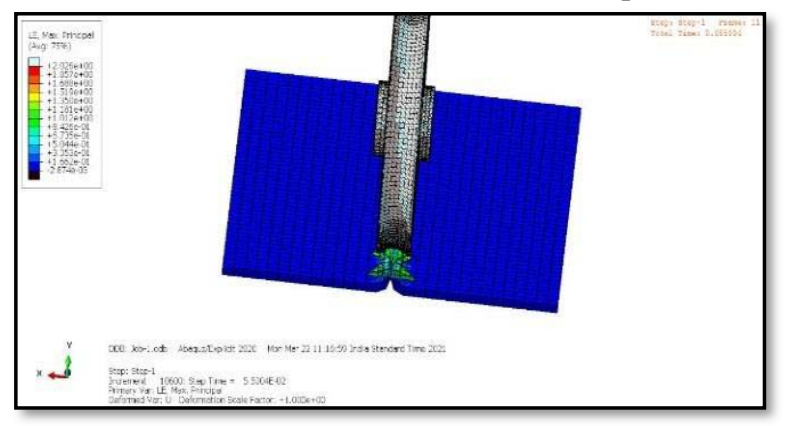

Fig. 8. Temperature distribution of $\mathrm{Cu}-\mathrm{DHP}$

show in Fig.10. As the tool continued to operate, the area of contact between the friction disc and the plate increased, As a result, more heat was generated and conducted to the plate, releasing heat to the environment, creating an asymmetric temperature distribution over the cross-section of the plate.

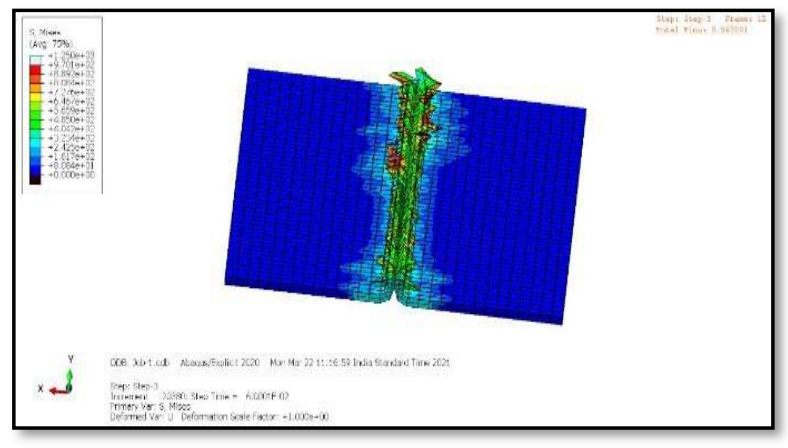

Fig. 9. Von misses stress distribution of $\mathrm{Cu}-\mathrm{DHP}$

the temperature contours of the plate in front of the tool were similar, which may indicate that the release and dissipation of heat kept the equilibrium in a nearly constant state. The maximum temperature was almost constant between 700 and $800^{\circ} \mathrm{C}$. As in Figure 8, the predicted temperature for the distance along a line 10 $\mathrm{mm}$ away from the groove of the tool centre on the flange surface to the ground surface agrees very well with the measured results. The maximum temperature is $780^{\circ} \mathrm{C}$ for $\mathrm{Cu}-\mathrm{DHP}$ and is reached near the centre of the tool.

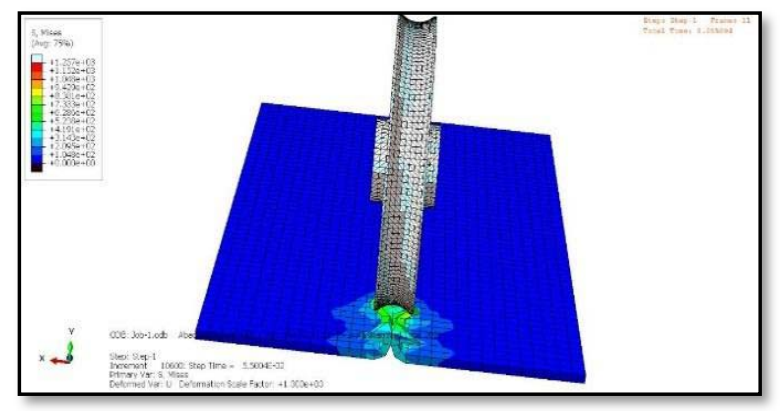

Fig. 10. Von misses stress distribution of AW-5754

\subsection{Effect of welding parameters}

Welding speed and tool speed are known to be two welding parameters that have a major effect on the flow of material in the weld and defects formation during the FCW process. In this study, both conditions were modeled using a FE model. Determining the effect of welding speed on deformation and equivalent plastic deformation, two welding speeds were chosen: 2000 $\mathrm{mm} / \mathrm{min}$ for AW-5754 and $7000 \mathrm{~mm} / \min$ for $\mathrm{Cu}-$ DHP. The plastic areas under the tool flange are enlarged to reduce welding speed. These results are similar to those of Besler et al.[6]. tool speed was selected at 18,000 rpm The large plasticized area under the tool groove is greater at higher tool speeds. Increased heat input can lead to increased plastic surface area and a smaller cavity at slower welding speeds or higher tool machining speeds, facilitating material flow.

\section{Conclusion}

A thermomechanical FE model based on the Coupled Eulerian-Lagrangian has been spread to investigate the FCW process for AW 5754 aluminium alloy and $\mathrm{Cu}-$ DHP copper alloy for similar material. The model is developed in Abaqus software and validated using temperatures published measurements and microscopic analysis of material flow.

From the analysis, it is observed that,

1. In the FCW forming stage, the temperature is distributed symmetrically over the crosssection of the specimen and the weld was Ushaped.

2. The temperature isotopes at the top and bottom of the plate gradually decreased.

3. The maximum working temperature is about $780 \mathrm{~K}$ below the minimum melting point of welding materials for AW-5754, which is about $1083 \mathrm{~K}$.

4. The model can predict the shape of the plastic deformation area.

5. The welding speed has the greatest influence on the mixing quality of the material obtained from the FCW process. However, the outcome depended on the material. Unsymmetrical 
mixing was found on the upper surface of the material.

6. The welding temperature is an important response to compare the welding crushing and the melting temperature of the base metal

7. Temperature behaviour during the process and the resulting crushing force appear to be an important factor when considering improvements in material flow. In future studies, tool diameter and shoulder size are other parameters that may be considered.

\section{References}

1. P. Kah, R. Rajan, J .Martikinanen, R. Suroranta, International Journal of Mechanical and Material Engineering, 10 ,1 (2015)

2. P. Cavaliere, A. Squillace, F. Panella, Journal of Materials Processing Technology, 200, 364 (2008)

3. M.R. Millan, G.D. Gonzalez, A. Rusinek, A. Arias, Metals, 8, 520 (2018)

4. M.A. Constantin, M.D. Iordache, E.L. Nitu , M. Diakhaté, Y. Demmouche, M. Dhondt, C. Badulescu, Materials Science and Engineering, 916, 012021 (2020)

5. F.A. Besler, P. Schindele, R.J. Grant, M.R.J. Stegmuller, Journal of Materials Processing Technology, 234,72 (2016)

6. F.A. Besler, R.J.Grant, P. Schindele, M.R.J. Stegmuller, Metallurgical and Materials Transactions B, 48, 2930 (2017)

7. G. S. Brar, A. S. Jamwal, I J A M R, 9, 101 (2017)

8. G.S. Brar, M. Singh, A.S. Jamwal, Process Parameter Optimization of Friction Crush Welding (FCW) of AISI 304Stainless Steel, Proceedings of the ASME International Mechanical Engineering Congress and Exposition (IMECE2017) 3-9, (Tampa, Florida, USA, 1-5.,2017)

9. P. Singh, D. Deepak, G. S. Brar, Materials Today: Proceedings, 1, 5 (2020)

10. A.S. Joma, A.D. Subhi, F.A. Hashim, Journal of Engineering Sciences, 13, 58 (2020)

11. P. Singh, D. Deepak, G.S. Brar, Optimization Of Friction Crush Welding Of Two Dissimilar Metals -Aluminium 6061 T-6 And Stainless Steel - AISI 304, Proceedings of the ASME $2020 \quad 15$ th International Manufacturing Science and Engineering Conference MSEC2020 June 22-26, (Cincinnati, OH, USA, 2020)

12. S. Mandal, J. Rice, A.A. Elmustafa, Journal of Materials Processing Technology, 203 , 411 (2008)

13. M. Yu, W. Y. Li, J. L. Li, Y. J. Chao, Materials Science and technology, 28, 812 (2012)

14. M. Hossfeld, E. Roos, A new approach to modelling friction stir welding using the CEL method, International Conference on Advanced Manufacturing Engineering and Technologies. (2013)
15. C. Wu, W. Zhang, L. Shi, M. Chen, Transactions of Nonferrous Metals Society of China, 22 , 1445 (2012)

16. M. Iordache, C. Badulescu, E. Niţu, D. Iacomi, Solid State Phenomena, 254, 272 (2016)

17. Z. Zhu, M. Wang, H. Zhang, X. Zhang, T. Yu, Z. Wu, Metals, 7 , 256 (2017)

18. J. Xiong, X. Peng, J. Shi, Y. Wang, J. Sun, X. Liu, J. Li, Materials Characterization 174, 110984 (2021)

19. M. Nourani, A. S. Milani, S. Yannacopoulos, C. Yan, The International Journal of Multiphysics, 8, 29 (2014)

20. N. K. Salloomi, Journal of Manufacturing Processes, 45, 746, (2019)

21. B. Ahmad, A. Galloway, A. Toumpis, Journal of Manufacturing Processes, 34, 625 (2018) 